\title{
Assessment of visceral pain associated with metritis in dairy cows
}

\author{
J. Stojkov, ${ }^{*}$ M. A. G. von Keyserlingk, ${ }^{*}$ J. N. Marchant-Forde,† and D. M. Weary ${ }^{\star 1}$ \\ *Animal Welfare Program, Faculty of Land and Food Systems, The University of British Columbia, Vancouver, BC, V6T 1 Z4 Canada \\ †USDA-Agricultural Research Service Livestock Behavior Research Unit, West Lafayette, IN 47907-2042
}

\begin{abstract}
Metritis is a common disease in dairy cattle, but to our knowledge, no work has assessed pain associated with this disease. Tissue palpation is commonly used to assess pain in human and veterinary medicine. The objective of this study was to evaluate visceral pain responses during rectal palpation, with and without uterine palpation, in healthy cows and in cows diagnosed with metritis. A total of 49 Holstein dairy cows (mean \pm standard deviation parity of $2.8 \pm 1.8$ ) were subjected to systematic health checks every $3 \mathrm{~d}$ after parturition for $21 \mathrm{~d}$, scoring for vaginal discharge (0 to 4); 13 cows showed a discharge score $\geq 2$ during at least 1 health check and were classified as metritic, whereas 29 cows were classified as healthy and showed no sign of this or any other disease (including mastitis and lameness). Back arch and heart rate variability before examination and during palpation were recorded using video and heart rate monitors. Back arch $\left(\mathrm{cm}^{2}\right)$ on the day of diagnosis was greater in metritic versus healthy cows $\left(1,034 \pm 72\right.$ vs. $\left.612 \pm 48 \mathrm{~cm}^{2}\right)$, and greater during rectal palpation with uterine palpation versus rectal palpation without uterine palpation $(869 \pm 45$ vs. $777 \pm$ $45 \mathrm{~cm}^{2}$ ). Heart rate frequency domain analysis showed that the low-frequency portion was higher in cows with metritis versus healthy cows $(16.5 \pm 1.2$ vs. $12.9 \pm$ 1.0). Time domain analysis showed that the standard deviation between normal to normal interbeat intervals and the root mean square of successive differences both decreased during rectal palpation with uterine palpation versus rectal palpation without uterine palpation $(1.9 \pm 0.1$ vs. $2.5 \pm 0.1$ and $1.3 \pm 0.1$ vs. $1.7 \pm 0.1$, respectively). Together, these results indicate that the inflammation associated with metritis is painful, and that the pain response can be detected during rectal palpation with and without uterine palpation. Rectal palpation with uterine palpation appears to be more aversive than rectal palpation without uterine palpa-
\end{abstract}

Received December 31, 2014.

Accepted April 19, 2015.

${ }^{1}$ Corresponding author: danweary@mail.ubc.ca tion, suggesting that the former should be avoided when possible.

Key words: rectal palpation, back arch, heart rate variability, pain behavior

\section{INTRODUCTION}

Physiological and pathological conditions can result in visceral pain in female reproductive organs. For example, humans sometimes report pelvic pain in the middle of the reproductive cycle, believed to be associated with ovarian follicle rupture and subsequent uterine contractions (Bonica et al., 1990). Pelvic pain is also associated with certain pathologies of the uterus, including postpartum metritis (Nelson et al., 1998), endometritis, and proliferation of the uterine mucosa (endometriosis; Bonica et al., 1990). Human patients diagnosed with deep infiltrated endometriosis also report a reduction in their subjective sense of wellbeing (Montanari et al., 2013).

Visceral pain in farm animals is mainly associated with severe gastrointestinal conditions, such as equine colic or traumatic reticuloperitonitis, and distension of abomasum or intestines in cattle (Radostits et al., 2007; Rialland et al., 2014). In cattle, back arch is considered as an indicator of hoof lesions (Flower and Weary, 2006) and as a diagnostic indicator for abdominal pain (Radostits et al., 2007). Parturition in cattle, thought to cause visceral pain in the dilatation phase and somatic pain in the expulsion phase (Lowe, 2002; Mainau and Manteca, 2011), is also associated with back arching (Houpt, 1991).

Responses to noxious stimuli provide one method of assessing visceral pain. Behavioral and physiological responses, such as flexion or withdrawal reflex, agitation while lying, generalized or regional muscle contractions, facial expression changes, cardiovascular, and respiratory changes, are associated with visceral pain (Ness and Gebhart, 1990; Rialland et al., 2014). Lumen distension or inflammation of certain hollow internal organs, such as the colon, bladder, and uterus, can initiate pain responses, but visceral organs are generally unresponsive to other damaging stimuli, such as cutting and burning (Cervero, 1994). Induced inflammation of the uterus 
evoked arching of the back and licking of the abdomen in mice (Wesselmann et al., 1998). Similar behavioral responses were reported in rats following inflammation of the colon (Laird et al., 2001). Collectively these studies suggest that uterine inflammation is likely to be painful in cattle.

Noxious stimulus of the uterine region is known to provoke cardiovascular and visceromotor responses (Ness and Gebhart, 1990). Visceral pain has been associated with cardiovascular responses, for example during colorectal distension in rabbits (Shafford and Schadt, 2008). Heart rate variability (HRV) changes in response to pain in sheep (Stubsjøen et al., 2009) and in response to internal and external stressors in cattle (Mohr et al., 2002). Heart rate variability can be used to assess the balance between sympathetic and parasympathetic activity of the autonomic nervous system and is considered a well-established, noninvasive method for detecting pain, stress, and pathological conditions in humans and other animals (von Borell et al., 2007).

Metritis is a common disease in cattle, with reported incidence ranging from 10 to $30 \%$ (Giuliodori et al., 2013). Culling rates in multiparous cows that develop metritis are approximately $30 \%$ higher compared with healthy cows (Wittrock et al., 2011). Metritis is known to induce behavioral and physiological changes including decreased feed intake, reduced milk production, and reduced competitiveness at the feeding bunk (Huzzey et al., 2007). To our knowledge, no study has assessed pain or even considered visceral pain as an underlying cause for these changes.

Tissue palpation, applied on a broad surface of an inflamed organ (Cervero, 1994), is a well-established method of evoking and thereby assessing pain (Ness and Gebhart, 1990; Radostits et al., 2007). Therefore, the objective of our study was to examine behavioral and physiological responses of dairy cattle during rectal palpation with and without uterine palpation in the days after calving. We hypothesized that transrectal uterine palpation would increase visceral pain in cows with metritis and that this pain would be associated with physiological and behavioral changes, specifically HRV and back arch. We predicted that the visceral pain provoked by palpation would increase the back arch in cows with metritis and would shift HRV toward sympathetic dominance, characteristic of painful conditions.

\section{MATERIALS AND METHODS}

The experiment was conducted at The University of British Columbia Dairy Education and Research Center (Agassiz, British Columbia, Canada). Care of the animals was according to the guidelines published by the Canadian Council on Animal Care (CCAC, 2009).

\section{Animals, Housing, and Management}

From July to September 2013, 49 Holstein dairy cows with mean $( \pm \mathrm{SD})$ parity of $2.8( \pm 1.8)$ were enrolled in the study. The average BW for the multiparous cows was (mean $\pm \mathrm{SD}$ ) $751 \pm 95 \mathrm{~kg}$ and for the primiparous cows was $662 \pm 82 \mathrm{~kg}$. All cows calved in an individual maternity pen but were then moved to a group pen where they were kept for $21 \mathrm{~d}$. The postpartum pen had 20 lying stalls, arranged in 2 rows. The stocking density throughout the study was maintained at $100 \%$. Each stall was fitted with a mattress and covered with $5 \mathrm{~cm}$ of sand. The postpartum pen had vulcanized rubber floors on the alleys and was equipped with 12 Insentec feed bins (Insentec, Marknesse, the Netherlands). Cows had ad libitum access to a TMR from the feed bins that were refilled twice daily at approximately 0800 and $1600 \mathrm{~h}$. Water was also provided ad libitum from 2 self-filling water troughs. Cows were milked twice daily in a double-12 parallel milking parlor at approximately 0700 and $1700 \mathrm{~h}$.

\section{Data Collection Using Videos and Heart Rate Monitors}

Cows were subjected to systematic health checks starting $3 \mathrm{~d}$ after parturition and continuing every $3 \mathrm{~d}$ for $21 \mathrm{~d}$. Immediately after the morning milking, cows were moved into the sorting area for health check. The sorting area was equipped with 1 water trough and cows were restrained using self-locking headlocks. Once the cow was restrained, colored wax markings (Livestock Paint Crayon, Carmel, Montreal, QC, Canada) were placed on her spine to monitor changes in back arch. A video camera (HDR-PJ380, Sony Corporation, Tokyo, Japan) recorded the cow at 60 frames per second, from a distance of $3 \mathrm{~m}$, and at a height of $1.45 \mathrm{~m}$ with an inclination (tilt) of $10^{\circ}$.

Heart rate monitors (HRM; Polar Equine RS800CX, Polar Electro Oy, Kempele, Finland) were used to measure the HRV of the cattle before and during the health checks, and were set to record interbeat intervals (R-R recording rate). The Polar HRM records heart rate from a distance and was previously validated for use in cows (Hopster and Blokhuis, 1994). Each HRM consists of an elastic strap, Wearlink transmitter, and watch receiver. The elastic strap had 2 incorporated electrodes and removable Wearlink transmitter attached, and was placed around the chest of each cow. Immediately before fitting the HRM, the left side of the cow's thorax and the lower part of the chest were soaked with warm 
water to improve conductivity between the electrodes and the cow's body. The upper electrode was located behind the left shoulder blade and the lower electrode placed near the sternum. After placing the elastic strap around the cow's chest, the watch was started. Previous studies have reported a period of 5 to $10 \mathrm{~min}$ as sufficient for animals to acclimate to the HRM equipment (Mohr et al., 2002; von Borell et al., 2007). In our study, cows were allowed to habituate to the equipment for approximately $10 \mathrm{~min}$. The trained examiner digitally marked each step of the health check procedure by pressing the lap button on the watch.

\section{Health Check Description}

The health checks were undertaken by a trained veterinarian and involved rectal cleaning, rectal palpation without uterine palpation, rectal palpation with uterine palpation, and, finally, vaginal discharge scoring. The veterinarian entered the rectal cavity with a lubricated hand (General Lube, First Priority Inc., Elgin, IL) and evacuated the feces from the rectum (mean duration \pm SD of this step: $34.0 \pm 5.5 \mathrm{~s}$ ). Cows were left undisturbed for approximately $1 \mathrm{~min}$ after the hand was removed. The examiner then re-entered the rectal cavity and placed the palm of his hand in a static position against the uterine wall (rectal palpation without uterine palpation) for $20 \mathrm{~s}$. The examiner then applied force for 20 $\mathrm{s}$ on the uterus in the direction of the pelvic wall (active phase). To estimate the force applied during the uterine palpation, the event was replicated under laboratory conditions using a Vernier Force Plate and Logger pro software (Vernier Software \& Technology, Beaverton, OR); force averaged $( \pm \mathrm{SD}) 96 \pm 11 \mathrm{~N}$. Finally, vaginal examination was conducted that involved cleaning the vulva with iodine solution (Prepodyne Scrub, Kane Veterinary Supplies, Edmonton, Alberta, Canada) and vaginal discharge collection by inserting a gloved hand into the vaginal canal. The vaginal discharge was scored following the method described by Huzzey et al. (2007); briefly, no mucus or clear mucus, no odor $=0$; cloudy mucus, with some pus or blood, no odor $=1$; mucopurulent (less than $50 \%$ pus) and foul smell $=2$; purulent (more than $50 \%$ pus) and foul smell $=3$; and putrid (red or brown color, watery, foul smell) $=4$. Cows with vaginal discharge scores of 0 or 1 during the entire 21-d observation period were considered healthy. Cows with vaginal discharge scores of 2,3 , and 4 were classified as having metritis. Data collected at the day of diagnosis represented the responses of metritic cows and was used for further analysis. Following diagnosis, cows were not subjected to any additional health checks. The average DIM at metritis diagnosis was 9 . Similarly, in healthy cows data were collected at 9 DIM.
Cows that developed lameness, displaced abomasum, severe vaginal or vulvar tears, mastitis, or that were treated with antibiotics or analgesics during the study were excluded from the trial $(\mathrm{n}=7)$.

\section{Variable Description and Calculation}

Back arch was defined as the 2-dimensional semicircular shape created by the curving spine (Figure 1). Wax body marks were placed on the highest thoracic vertebra (A) and on the first coccygeal vertebra (B) and the 2 lines that connected these body marks were used to define the area of back arch. The base of the semicircle (i.e., the minimum distance from A to B) was used in the analysis to control for the difference in size between cows. Measurements were from photos using Adobe Photoshop CS6 (Adobe Systems, San Jose, $\mathrm{CA}$ ); the number of pixels from the selected 2-dimensional semicircular area were converted into centimeters squared that corresponded with the actual area of back arch on the cow. Back arch was assessed during rectal palpation without uterine palpation using 4 snapshots taken $4,8,12$, and $16 \mathrm{~s}$ from the onset of this phase; these 4 values were then averaged. This procedure was repeated for the rectal palpation with the uterine palpation phase. Back arch before examination was assessed from 2 snapshots at 10 and $20 \mathrm{~s}$ before rectal cleaning commenced and these values were also averaged. Back arch was quantified for 42 cows (15 primiparous and 27 multiparous); of these, 29 were healthy and 13 metritic. The difference in back arch between healthy and metritic cows was of a primary interest in our study and was the basis for calculating the sample size. Based on the data from previous pilot project conducted in our laboratory, metritic cows had, on average, $447 \mathrm{~cm}^{2}$ (SD = 220) more pronounced back arch compared with heathy cows. Power analysis before the study indicated that 10 animals per group (10 healthy +10 metritic) would detect the difference in back arch between healthy and metritic cows of $400 \mathrm{~cm}^{2}(\mathrm{SD}=290)$ and provide power greater than 0.8 .

Intra- and interobserver agreement for back arch was calculated using 20 randomly selected photos. According to the recommendations by Bland and Altman (2003), in cases when a consistent difference between measurements (e.g., first and second measurement) and no consistent bias was observed, correlation should be used to estimate agreement. Therefore, the differences within and between observers were analyzed using the intraclass correlation coefficient. All of the estimates of agreement were excellent ( $\mathrm{r}>0.99)$.

Heart rate (HR) data were downloaded and analyzed using the Polar Pro Trainer 5 Equine Edition software (Polar Electro Oy). These data were displayed graphi- 


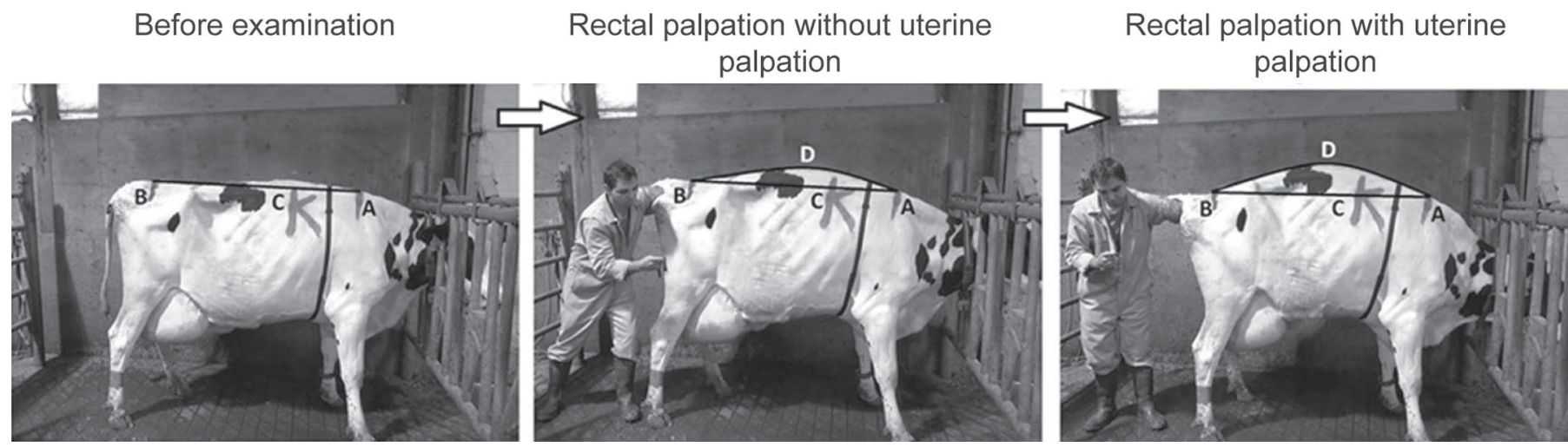

Figure 1. Back arch before examination and during rectal palpation without uterine palpation and rectal palpation with uterine palpation. Two wax body marks were placed on the spine; the first (A) near the shoulder (highest thoracic vertebrae) and the second on the first coccygeal vertebrae (B). The straight line (C) connecting A with B created the base of the semicircle. A second line (D) followed the spine and reconnected body marks $\mathrm{A}$ and $\mathrm{B}$. The combination of $\mathrm{C}$ and $\mathrm{D}$ formed a semicircle; this area (measured in $\mathrm{cm}^{2}$ ) was used to quantify back arch.

cally and visually inspected for presence of the 5 types of anomalies as described by Marchant-Forde and colleagues (2004). Visual inspection was conducted before and after the error-correction filter was applied. The anomalies were initially corrected using the automatic Polar Pro Trainer 5 error-correction filter set at moderate mode (default setting). The setting was changed to very high mode to edit specific artifacts that were not successfully handled using the default setting (this proved necessary to correct HRV data for 10 cows). Files that contained more than $5 \%$ anomalies were excluded from the analysis (von Borell et al., 2007). Once edited, data were analyzed using the built-in time domain and frequency domain functions of the Polar Pro Trainer 5 software. The frequency bands were set to 0.00 to 0.04 $\mathrm{Hz}$ for the very low frequency (VLF), 0.04 to $0.20 \mathrm{~Hz}$ for the low frequency $(\mathbf{L F})$, and 0.20 to $0.58 \mathrm{~Hz}$ for the high frequency $(\mathbf{H F})$, adjusted for the respiratory rate in cattle (Kamath and Fallen, 1993; Mohr et al., 2002; von Borell et al., 2007). Two different time periods were selected to analyze the HRV measures. The first time period before examination started $10 \mathrm{~min}$ after the HRM were attached and lasted for $5 \mathrm{~min}$, the duration recommended by the Task Force of the European Society of Cardiology and the North American Society of Pacing and Electrophysiology (Malik et al., 1996). The cows were in a stationary position and no examination was conducted at this point. Both time and frequency domain measures were extracted and used in the analysis for HRV before examination. In the time domain, standard deviation between normal to normal interbeat intervals (SDNN), root of the mean square of successive differences (RMSSD), and average interbeat interval (IBI) were extracted. The frequency domain measures included total power, VLF, LF, HF, and the LF-to-HF ratio. Total power incorporates the variance of the IBI over the observed HR segment and frequency range between 0 and $0.58 \mathrm{~Hz}$. The VLF, LF, and HF were expressed as percentage of total power (e.g., LF/ total power; VLF\%, LF\%, and HF\%; von Borell et al., 2007). The second time period (during rectal palpation with and without uterine palpation) contained 2 sections of 20 IBI each selected during rectal palpation with and without uterine palpation. Segments were selected starting at $4 \mathrm{~s}$ from the onset of the procedure and lasted approximately (mean \pm SD) $14 \pm 1$ s. Due to the short duration of these recordings, only time domain analysis was conducted and included SDNN, RMSSD, and average IBI (Thong et al., 2003). The HRV measures during examination were calculated for 42 cows (29 healthy and 13 metritic). However, 4 metritic cows were excluded from the analysis due to the anomalies in the HR data after the error-correction filter was applied, reducing the sample size to 38 cows (29 healthy and 9 metritic). The sample for HRV measures before examination included an additional 15 cows. Cows that did not provide 512 IBI or showed anomalies in the data after the error-correction filter was applied were excluded from the analysis $(\mathrm{n}=10)$. In total, HRV measures before examination were calculated and analyzed for 47 cows (30 healthy and 17 metritic), consisting of 16 primiparous and 31 multiparous cows.

\section{Statistical Analysis}

Statistical analyses were conducted using SAS (version 9.3, SAS Institute Inc., Cary, NC). The UNIVARIATE procedure was used to scan for normality and outliers. Three different models were used. (1) One-way ANOVA was used to test the effect of health status (healthy vs. metritic) on the back arch prior examination, after parity was excluded from the model as not 
significant. (2) Two-way ANOVA was used to determine the effect of health status (healthy vs. metritic) and parity (primiparous vs. multiparous) on the HRV measures before examination. Least squares means were calculated from the models and reported in the Results section. (3) The effects of health status, examination method, parity, and DIM on back arch, and HRV measures during rectal palpation without uterine palpation and rectal palpation with uterine palpation were tested using a mixed model, with cow specified as a random variable. The size of the base of the semicircle $(\mathrm{AB})$ was used as a covariate in the model to test the effect on the back arch. As the effect of parity, DIM, and size of $\mathrm{AB}$ were not significant, the final model included only the health status (healthy cows vs. cows with metritis), type of exam (rectal palpation without uterine palpation vs. rectal palpation with uterine palpation), and the interaction. Residuals from each model were checked for homoscedasticity and normality. In all cases interactions were only reported when $P<0.1$.

The LF-to-HF ratio, $\mathrm{VLF} \%, \mathrm{LF} \%$, and $\mathrm{HF} \%$ from the frequency domain, SDNN, RMSSD, and average IBI from the time domain were used in the analyses. The presence of outliers and skewness of HF\% and LFto-HF ratio measures in the HRV before examination required that these data be log-transformed. Similarly, SDNN and RMSSD from the HRV during rectal palpation with and without uterine palpation were logtransformed to normalize errors.

\section{RESULTS}

Back arch before examination tended to be higher in metritic versus healthy cows $\left(119 \pm 47\right.$ vs. $17 \pm 32 \mathrm{~cm}^{2}$; $\left.\mathrm{F}_{1,40}=3.3 ; P=0.08\right)$. During the rectal palpation with and without uterine palpation, back arch was greater in cows with metritis than in healthy cows $(1,034 \pm$ 73 vs. $613 \pm 49 \mathrm{~cm}^{2} ; \mathrm{F}_{1,40}=23.2 ; P<0.001 ;$ Figure 2). Regardless of health status, the back arch was also greater during the rectal palpation with uterine palpation compared with the rectal palpation without uterine palpation $\left(869 \pm 45\right.$ vs. $778 \pm 45 \mathrm{~cm}^{2} ; \mathrm{F}_{1,40}=$ 18.4; $P<0.001)$.

Before examination, parity affected both time and frequency domain HRV measures (IBI, VLF\%, and LF\%). Health status only affected frequency domain HRV measures (Table 1). The IBI and LF\% were 47.8 $\mathrm{ms}$ and 5.4 units higher in multiparous cows, respectively $\left(737.4 \pm 12.5\right.$ vs. $689.6 \pm 15.7 \mathrm{~ms} ; \mathrm{F}_{1,43}=5.6$; $P=0.02$ and $17.4 \pm 1.0$ vs. $12.0 \pm 1.3$ percentage units; $\mathrm{F}_{1,43}=10.6 ; P<0.01$, respectively). In contrast, VLF\% was 5.1 units lower in multiparous cows $(81.8$ \pm 1.0 vs. $86.9 \pm 1.3$ percentage units; $\mathrm{F}_{1,43}=9.7 ; P<$
0.01). Differences between healthy and metritic cows were observed for VLF\% and $\mathrm{LF} \%$; LF\% was 3.6 units higher in metritic cows and VLF\% was 3.9 units lower in metritic cows.

Time domain measures of HRV were lower during rectal palpation with uterine palpation than during the rectal palpation without uterine palpation $\left(\mathrm{SDNN}: \mathrm{F}_{1,36}\right.$ $=9.6, P<0.01$; RMSSD: $\mathrm{F}_{1,36}=9.8, P<0.01$; Figure $3)$. Rectal palpation with uterine palpation decreased SDNN and RMSSD by about $25 \%$ compared with rectal palpation without uterine palpation (Figure 3). No difference in IBI was observed during rectal palpation without uterine palpation versus rectal palpation with uterine palpation $(706.8 \pm 13.6$ vs. $708.6 \pm 13.6$ $\mathrm{ms}$, respectively), and no interaction between parity and health status for any HRV measure. Health status had no significant influence on the HRV time domain measures during examination. The SDNN for healthy versus metritic cows averaged $2.2 \pm 0.1$ and $2.3 \pm 0.2$ $\mathrm{ms}$, RMSSD averaged $1.4 \pm 0.1$ versus $1.6 \pm 0.1 \mathrm{~ms}$, and IBI averaged $718.4 \pm 13.1$ versus $696.9 \pm 23.6 \mathrm{~ms}$, respectively.

\section{DISCUSSION}

\section{Back Arch}

Back arch in response to visceral pain has been previously reported in studies on laboratory rats with induced uterine inflammation (Wesselmann et al., 1998) and mice with induced colon inflammation (Laird et al., 2001). To our knowledge, ours is the first study to

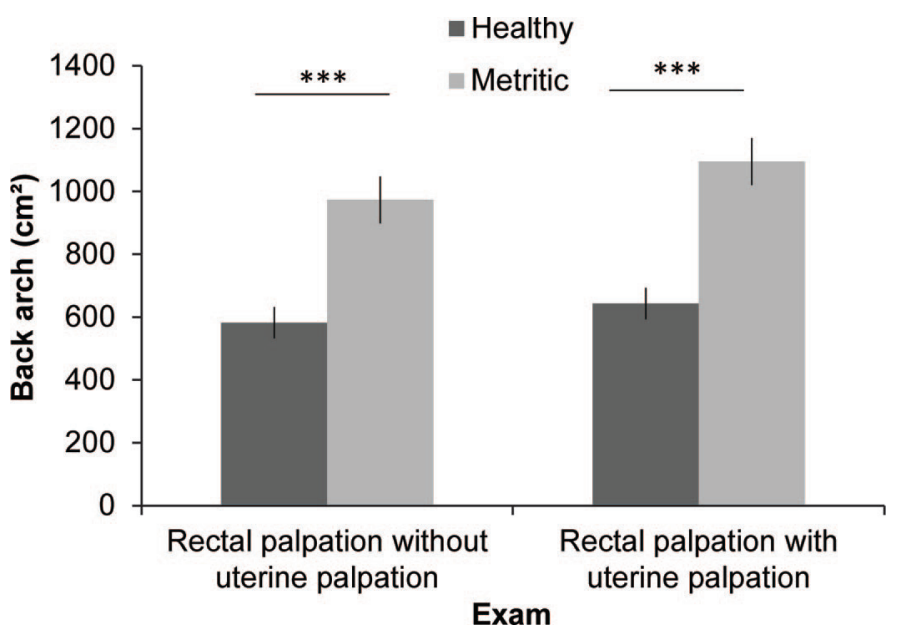

Figure 2. Least squares means \pm SE back arch during rectal palpation without uterine palpation and rectal palpation with uterine palpation for healthy cows $(\mathrm{n}=29)$ and those diagnosed with metritis $(\mathrm{n}=13)$. Three asterisks $(* * *)$ indicates $P<0.001$. 
Table 1. Least squares means $\pm \mathrm{SE}$ heart rate variability before examination, shown for healthy $(\mathrm{n}=30)$ and metritic cows $(\mathrm{n}=17)^{1}$

\begin{tabular}{|c|c|c|c|}
\hline \multirow[b]{2}{*}{ Heart rate variability parameter } & \multicolumn{2}{|c|}{ Health status } & \multirow[b]{2}{*}{$P$-value } \\
\hline & $\begin{array}{c}\text { Healthy } \\
\text { cows }\end{array}$ & $\begin{array}{l}\text { Metritic } \\
\text { cows }\end{array}$ & \\
\hline SDNN (ms) & $17.2 \pm 1.2$ & $17.0 \pm 1.4$ & 0.926 \\
\hline RMSSD (ms) & $4.4 \pm 0.4$ & $4.9 \pm 0.4$ & 0.359 \\
\hline Average interbeat interval (ms) & $719.2 \pm 13.1$ & $707.8 \pm 15.4$ & 0.569 \\
\hline $\operatorname{VLF}(\%)$ & $86.3 \pm 1.1$ & $82.4 \pm 1.3$ & 0.022 \\
\hline $\mathrm{LF}(\%)$ & $12.9 \pm 1.0$ & $16.5 \pm 1.2$ & 0.028 \\
\hline $\operatorname{lnHF}(\%)$ & $-0.8 \pm 0.2$ & $-0.2 \pm 0.2$ & 0.091 \\
\hline $\operatorname{lnLF}: \mathrm{HF}$ ratio & $7.8 \pm 0.2$ & $7.6 \pm 0.2$ & 0.533 \\
\hline
\end{tabular}

${ }^{1}$ Time domain measures SD of normal to normal inter beat intervals (SDNN) and root mean square of successive differences (RMSSD) are presented in milliseconds (ms); very low frequency (VLF), low frequency $(\mathrm{LF})$, and high frequency (HF) expressed as percentage of total power; HF\% and LF-to-HF ratio were logtransformed (ln).

objectively measure back arch in response to visceral pain associated with metritis, and the first to use this measure to assess pain in naturally occurring cases of disease in any species.

Cows with metritis responded to rectal palpation with and without uterine palpation. This pronounced back arch was likely associated with pain that accompanied inflammation of the uterine wall; inflammation and ischemia of the viscera are considered to be noxious visceral stimuli (Ness and Gebhart, 1990). The results from our study suggest that metritic cows have uterine hyperalgesia. Inflammation of the internal organs may activate receptors, contributing to increased sensitivity during palpation (Cervero and Laird, 1999). Similarly, pain associated with appendicitis can lower pain thresh- olds to the extent that the motility of the surrounding intestines becomes painful (Cervero, 1994).

Back arching in cattle is associated with both physiological and pathological conditions. From a physiological perspective, back arching is associated with urination, defecation, and parturition (Houpt, 1991; Pilz et al., 2012). Pathologically, back arching is associated with hoof lesions and is a well-established criterion to assess lameness (Sprecher et al., 1997; Flower and Weary, 2006). Back arch is also used for diagnosis of abdominal pain caused by peritonitis, traumatic reticuloperitonitis, and abomasal volvulus (Radostits et al., 2007). The presence of back arch in cattle with inflammation of the peritoneum and the adjacent visceral organs is consistent with the hypothesis that inflamma-

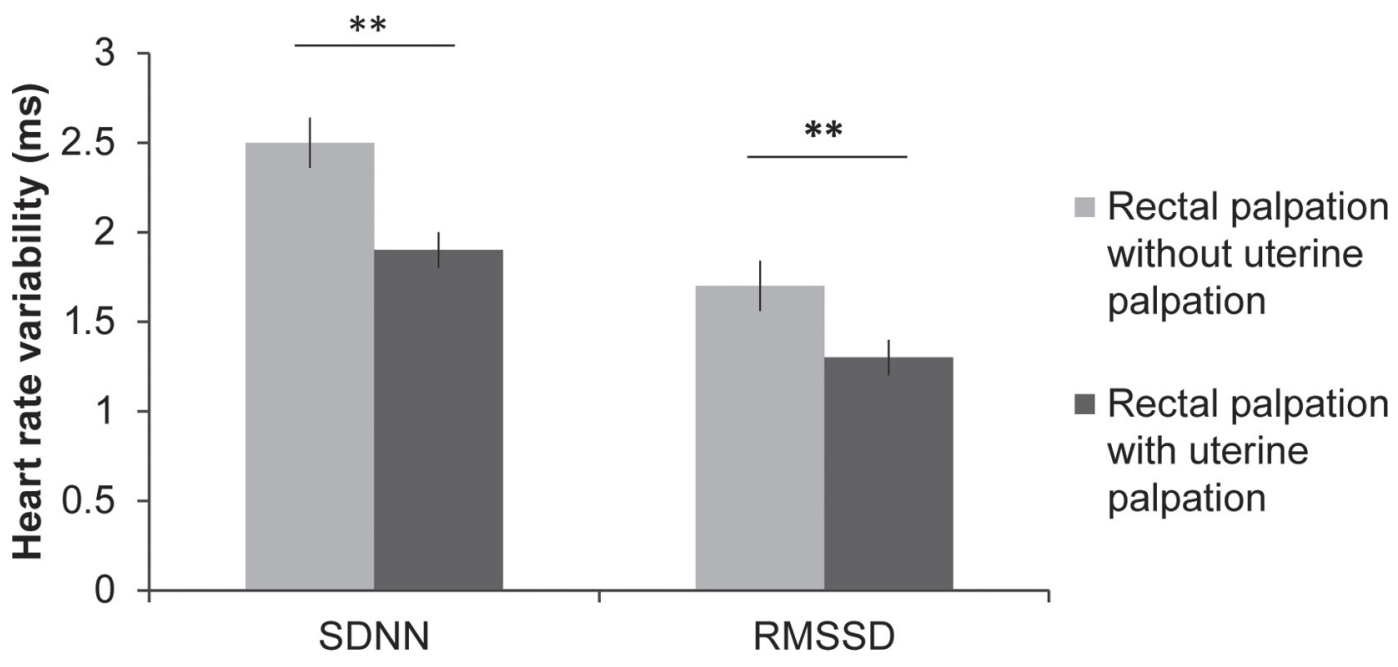

Time Domain Measures

Figure 3. Least squares means $\pm \mathrm{SE}$ of 2 temporal measures of heart rate variability: log-transformed standard deviation of normal to normal inter beat intervals (SDNN) and log-transformed root mean square of successive differences $(\mathrm{RMSSD})$. Results are shown for cows $(\mathrm{n}=$ 38 ) undergoing rectal palpation without uterine palpation and rectal palpation with uterine palpation. Two asterisks $(* *)$ indicates $P<0.01$. 
tion of the viscera causes back arching. Back arch has also been reported during vaginal examination (Pilz et al., 2012).

Back arch has also been reported as a pain response following abdominal surgery in sea lions (Walker et al., 2009) and rats (Roughan and Flecknell, 2001). The latter authors have advocated including back arch into a scoring system for abdominal pain.

Although the majority of the fecal material within the rectum had been removed, insertion of the hand and arm may have induced a defecation response that is often accompanied by an arched back. However, the differences between healthy and metritic cows cannot be accounted for by the defecation reflex (Pilz et al., 2012). We suggest that the observed differences are a consequence of visceral pain in cows with an inflamed uterus. Visceral pain is often projected (referred) to other regions of the body (Wesselmann and Lai, 1997). Referred visceral pain was previously reported in studies in humans (Giamberardino et al., 1997) and laboratory animals (Wesselmann and Lai, 1997). Rats with an inflamed uterus show evidence of referred pain around the abdomen, groin, lower back, thighs, and perineal area (Wesselmann and Lai, 1997). Similarly, studies have found that visceral pain stimulates the adjacent viscera, inducing viscero-visceral hyperalgesia (Cervero, 2000; Giamberardino et al., 2001, 2010). Brinkert and colleagues (2007) showed that menstrual pain causes hyperalgesia in the sigmoid colon and the rectum. Considering the proximity of the rectal segment involved in the palpation and the inflamed uterus, we suggest that the back arching during rectal palpation without uterine palpation in metritic cows can be attributed to the visceral hyperalgesia of the rectum.

Back arch was greater during rectal palpation with uterine palpation than during rectal palpation without uterine palpation. Transrectal palpation is a common method for assessing the condition of the reproductive organs in dairy cows, so this provides a practical method for applying noxious stimuli to internal organs such as the uterus. However, during the uterine palpation the rectal wall is involved as a mediator (i.e., the force is applied to the uterus via the rectal wall). Thus, the response should be considered due to the combined effects of uterine and rectal sensitivity. Future studies could quantify how much the rectum contributes to the back arch by applying similar force on the rectum in a direction away from the uterus. In addition, manual uterine palpation limited the amount of time the force could be applied to the uterine body and likely introduced variation in the force applied between observations. Future studies should consider using an instrument instead of the examiner's arm (e.g., pressure balloons). This approach could provide longer intervals (perhaps long enough to assess 512 IBI suitable for spectral analysis). This method may be useful in establishing the range of stimuli that initiates pain, and assess the sensitivity of back arch as a measure to visceral pain.

Different types of metritis might cause different degrees of uterine inflammation and different pain responses. Metritis is an acute inflammation of the uterus that usually occurs in the first $21 \mathrm{~d}$ after calving. Clinical signs include foul-smelling, red-brown, watery uterine discharge, dullness, inappetance, pyrexia, increased HR, and reduced milk yield described as puerperal metritis (Sheldon et al., 2006). Metritis can also occur in a milder form where animals lack the symptoms of systematic illness but have an enlarged uterus and purulent uterine discharge, described as clinical metritis (Sheldon et al., 2006). The differences between puerperal and clinical metritis, especially the signs of systematic illness and fever in the puerperal cases, might be related to the degree of uterine inflammation and might affect pain expression. The small number of cows with puerperal metritis in the current study prevented a meaningful test of differences between cases of puerperal and clinical metritis.

\section{HRV Before Examination}

The low-frequency portion of HRV reflects both sympathetic and parasympathetic branch of the autonomic nervous system (Malik and Camm, 1995). However, LF is considered to reflect mainly sympathetic activity (Malik et al., 1996). Uterine pain is mediated by sympathetic nerves, and blocking the sympathetic innervations of the uterus reduces visceromotor reflexes caused by uterine distension in animals and pain during labor in women (Cervero, 1994). Sympathetic activation projected as increased HR and decreased HRV has been related to postlaparotomy pain in mice (Arras et al., 2007), noxious ischemic stimulus in sheep (Stubsjøen et al., 2009), and visceral pain in rabbits (Shafford and Schadt, 2008). Moreover, an increase in $\mathrm{LF}$ in response to acute pain is reported in studies with human subjects (Terkelsen et al., 2005). Increased LF\% in the present study suggests that the pain in cows with metritis contributes to sympathetic activation (Jänig,, 1995; Terkelsen et al., 2005). The VLF component of the HRV is associated with both sympathetic and parasympathetic activity, making these differences more difficult to interpret (Malik et al., 1996; von Borell et al., 2007).

The LF-to-HF ratio is considered as an indicator of sympathovagal balance (Malik et al., 1996; von Borell et al., 2007). However, the increased LF portion in our 
study did not result in changes in the LF-to-HF ratio. The absence of changes in the LF-to-HF ratio might be related to the diffuse localization and mild intensity of visceral pain associated with metritis. Similarly, Yamamoto et al. (1991) reported increased LF portion without changes in LF-to-HF ratio during exercise with lower intensity. However, both LF and LF-to-HF ratio increased when the intensity of exercise increased, suggesting a positive relationship between intensity and changes in LF-to-HF ratio.

Before the examination, IBI and LF\% were lower in primiparous versus multiparous cows. Studies in humans have found increased HRV with aging, suggesting a shift in the sympathovagal balance toward parasympathetic dominance due to maturation of the autonomic nervous system (Silvetti et al., 2001). Overall, the activity of both branches of the autonomic nervous system is expected to decline with age (Shimazu et al., 2005; Yukishita et al., 2010).

\section{HRV During Rectal Palpation With and Without Uterine Palpation}

Two time domain measures of HRV, SDNN and RMSSD, differed with the type of examination performed. The SDNN reflects the long-term variability of HRV and is considered an indicator of both sympathetic and vagal activity (Mohr et al., 2002; von Borell et al., 2007); RMSSD indicates short-term variability and primarily reflects vagal activity (von Borell et al., 2007). The RMSSD is also considered as a reliable ultra-short HRV measure, even when using intervals as short as 10 s (Thong et al., 2003). In our study, both measures decreased during the rectal palpation with uterine palpation compared with during rectal palpation without uterine palpation, suggesting that the uterine palpation was more painful. Previous studies have reported that sympathetic afferents mediate painful sensations from the uterus (Cervero, 1994), and that uterine palpation can result in cardiovascular and visceromotor responses (Ness and Gebhart, 1990). The decreased SDNN and RMSSD suggest that overall HR variability is decreased and that the sympathovagal balance shifted toward sympathetic dominance. Previous studies related to stress and visceral and somatic pain are consistent with the current results. Induced stress in calves decreased both SDNN and RMSSD (Porges, 1995; Mohr et al., 2002). In addition, an internal stress factor (diarrhea) that might be accompanied by abdominal pain resulted in a more intense decline of these measures (Mohr et al., 2002). In humans, heart-related pain is associated with a reduction in HRV, suggesting that cardiac pain shifts the autonomic balance toward the sympathetic dominance (Ruggeri et al., 1996). Similarly, Yap et al. (2000) found that the sympathovagal balance shifts toward sympathetic dominance when the HRV is reduced; SDNN is also decreased in humans subjected to pain (Meeuse et al., 2013). In summary, these results suggest that pain is greater during rectal palpation with uterine palpation compared with rectal palpation without uterine palpation in both healthy and metritic cows.

The results from the current study extend our knowledge of pain assessment, but are not immediately applicable in the field. The HRV analysis is not practical for cow-side assessment of pain, at least not with the techniques used in the current study. Back arch may be more useful for routine pain assessment in the field; this measure is currently used in the clinical assessment of lameness, and we encourage future work to determine if visual assessments of back arch could also provide realtime assessments of pain responses during palpation.

\section{CONCLUSIONS}

Back arch during rectal palpation without uterine palpation and rectal palpation with uterine palpation can be used to assess visceral pain in dairy cattle. The spectral analysis of HRV indicates that metritis is painful, contributing to increased sympathetic activity. Time domain measures also indicated that rectal palpation with uterine palpation was more painful than rectal palpation without uterine palpation, suggesting that the former should be avoided when possible.

\section{ACKNOWLEDGMENTS}

We thank the staff and students at The University of British Columbia's Dairy Education and Research Centre. The authors are grateful to Julie Huzzey and Julia Lomb (Animal Welfare Program, Vancouver, BC, Canada) for assisting with handling and data collection and to Doug Viera (Agriculture and Agri-Food Canada, Agassiz, BC, Canada) for lending us the heart rate monitors. This research was funded by a Discovery Grant to D. M. Weary from Canada's Natural Sciences and Engineering Research Council (NSERC, Ottawa, ON, Canada). University of British Columbia's Animal Welfare Program is funded by NSERC's Industrial Research Chair Program with industry contributions from the Dairy Farmers of Canada (Ottawa, ON, Canada), British Columbia Dairy Association (Burnaby, BC Canada), Westgen Endowment Fund (Milner, BC, Canada), Intervet Canada Corporation (Kirkland, QC, Canada), Zoetis (Kirkland, QC, Canada), BC Cattle Industry Development Fund (Kamloops, BC, Canada), 
Alberta Milk (Edmonton, AB, Canada), Valacta (St. Anne-de-Bellevue, QC, Canada), and CanWest DHI (Guelph, ON, Canada).

\section{REFERENCES}

Arras, M., A. Rettich, P. Cinelli, H. P. Kasermann, and K. Burki 2007. Assessment of post-laparotomy pain in laboratory mice by telemetric recording of heart rate and heart rate variability. BMC Vet. Res. 3:16.

Bland, J. M., and D. G. Altman. 2003. Applying the right statistics: Analyses of measurement studies. Ultrasound Obstet. Gynecol. 22:85-93.

Bonica, J. J., J. D. Loeser, C. R. Chapman, and W. E. Fordyce. 1990 The Management of Pain. Vol. 1. Lea \& Febiger, Philadelphia, PA.

Brinkert, W., G. Dimcevski, L. Arendt-Nielsen, A. M. Drewes, and O. H. Wilder-Smith. 2007. Dysmenorrhoea is associated with hypersensitivity in the sigmoid colon and rectum. Pain 132:S46-S51.

CCAC (Canadian Council on Animal Care). 2009. CCAC Guidelines On: The Care and Use of Farm Animals in Research, Teaching and Testing. CCAC, Ottawa, Ontario, Canada.

Cervero, F. 1994. Sensory innervation of the viscera: Peripheral basis of visceral pain. Physiol. Rev. 74:95-138.

Cervero, F. 2000. Visceral hyperalgesia revisited. Lancet 356:11271128 .

Cervero, F., and J. Laird. 1999. Visceral pain. Lancet 353:2145-2148.

Flower, F. C., and D. M. Weary. 2006. Effect of hoof pathologies on subjective assessments of dairy cow gait. J. Dairy Sci. 89:139-146.

Giamberardino, M. A., K. J. Berkley, S. Iezzi, P. de Bigontina, and L. Vecchiet. 1997. Pain threshold variations in somatic wall tissues as a function of menstrual cycle, segmental site and tissue depth in non-dysmenorrheic women, dysmenorrheic women and men. Pain $71: 187-197$.

Giamberardino, M. A., R. Costantini, G. Affaitati, A. Fabrizio, D. Lapenna, E. Tafuri, and A. Mezzetti. 2010. Viscero-visceral hyperalgesia: characterization in different clinical models. Pain 151:307-322

Giamberardino, M. A., S. De Laurentis, G. Affaitati, R. Lerza, D. Lapenna, and L. Vecchiet. 2001. Modulation of pain and hyperalgesia from the urinary tract by algogenic conditions of the reproductive organs in women. Neurosci. Lett. 304:61-64.

Giuliodori, M. J., R. P. Magnasco, D. Becu-Villalobos, I. M. LacauMengido, C. A. Risco, and R. L. de la Sota. 2013. Metritis in dairy cows: Risk factors and reproductive performance. J. Dairy Sci. 96:3621-3631

Hopster, H., and H. J. Blokhuis. 1994. Validation of a heart-rate monitor for measuring a stress response in dairy cows. Can. J. Anim. Sci. 74:465-474.

Houpt, K. A. 1991. Domestic Animal Behavior for Veterinarians and Animal Scientists. Wiley-Blackwell, Hoboken, NJ.

Huzzey, J. M., D. M. Veira, D. M. Weary, and M. A. G. von Keyserlingk. 2007. Prepartum behavior and dry matter intake identify dairy cows at risk for metritis. J. Dairy Sci. 90:3220-3233.

Jänig, W. 1995. The sympathetic nervous system in pain. Eur. J. Anaesthesiol. Suppl. 10:53-60.

Kamath, M. V., and E. L. Fallen. 1993. Power spectral analysis of heart rate variability: A noninvasive signature of cardiac autonomic function. Crit. Rev. Biomed. Eng. 21:245-311.

Laird, J. M. A., L. Martinez-Caro, E. Garcia-Nicas, and F. Cervero, 2001. A new model of visceral pain and referred hyperalgesia in the mouse. Pain 92:335-342.

Lowe, N. K. 2002. The nature of labor pain. Am. J. Obstet. Gynecol. 186:S16-S24

Mainau, E., and X. Manteca. 2011. Pain and discomfort caused by parturition in cows and sows. Appl. Anim. Behav. Sci. 135:241-251.

Malik, M., J. T. Bigger, A. J. Camm, R. E. Kleiger, A. Malliani, A. J. Moss, and P. J. Schwartz. 1996. Heart rate variability standards of measurement, physiological interpretation, and clinical use. Eur. Heart J. 17:354-381.
Malik, M., and A. J. Camm. 1995. Heart Rate Variability. Futura Pub. Co., Armonk, NY.

Marchant-Forde, R. M., D. J. Marlin, and J. N. Marchant-Forde. 2004. Validation of a cardiac monitor for measuring heart rate variability in adult female pigs: Accuracy, artefacts and editing. Physiol. Behav. 80:449-458.

Meeuse, J. J., M. S. Löwik, S. A. Löwik, E. Aarden, A. M. Roon, R. O. Gans, M. van Wijhe, J. D. Lefrandt, and A. K. Reyners. 2013 Heart rate variability parameters do not correlate with pain intensity in healthy volunteers. Pain Med. 14:1192-1201.

Mohr, E., J. Langbein, and G. Nürnberg. 2002. Heart rate variability: A noninvasive approach to measure stress in calves and cows. Physiol. Behav. 75:251-259.

Montanari, G., N. Di Donato, A. Benfenati, G. Giovanardi, L. Zannoni, C. Vicenzi, S. Solfrini, G. Mignemi, G. Villa, M. Mabrouk, C. Schioppa, S. Venturoli, and R. Seracchioli. 2013. Women with deep infiltrating endometriosis: Sexual satisfaction, desire, orgasm, and pelvic problem interference with sex. J. Sex. Med. 10:1559-1566.

Nelson, D. B., R. B. Ness, J. F. Peipert, D. E. Soper, A. J. Amortegui, J. Gluck, H. Wiesenfeld, and P. A. Rice. 1998. Factors predicting upper genital tract inflammation among women with lower genital tract infection. J. Womens Health 7:1033-1040.

Ness, T. J., and G. F. Gebhart. 1990. Visceral pain: A review of experimental studies. Pain 41:167-234.

Pilz, M., C. Fischer-Tenhagen, G. Thiele, H. Tinge, F. Lotz, and W. Heuwieser. 2012. Behavioural reactions before and during vaginal examination in dairy cows. Appl. Anim. Behav. Sci. 138:18-27.

Porges, S. W. 1995. Orienting in a defensive world: Mammalian modifications of our evolutionary heritage. A polyvagal theory. Psychophysiology 32:301-318.

Radostits, O. M., C. C. Gay, K. W. Hinchcliff, and P. D. Constable. 2007. Veterinary Medicine: A Textbook of the Diseases of Cattle, Horses, Sheep, Pigs and Goats. 10th ed. Saunders, Philadelphia, PA.

Rialland, P., C. Otis, M. L. de Courval, P. Y. Mulon, D. Harvey, S. Bichot, D. Gauvin, A. Livingston, F. Beaudry, P. Hélie, D. Frank, J. R. E. del Castillo, and E. Troncy. 2014. Assessing experimental visceral pain in dairy cattle: A pilot, prospective, blinded, randomized, and controlled study focusing on spinal pain proteomics. J. Dairy Sci. 97:2118-2134.

Roughan, J. V., and P. A. Flecknell. 2001. Behavioural effects of laparotomy and analgesic effects of ketoprofen and carprofen in rats. Pain 90:65-74.

Ruggeri, A., A. Pozzati, M. L. Loricchio, G. Premuda, A. Borghi, and R. Bugiardini. 1996. Influence of pain on heart rate variability during Holter monitoring. J. Am. Coll. Cardiol. 27:382-383.

Shafford, H. L., and J. C. Schadt. 2008. Effect of buprenorphine on the cardiovascular and respiratory response to visceral pain in conscious rabbits. Vet. Anaesth. Analg. 35:333-340.

Sheldon, I. M., G. S. Lewis, S. LeBlanc, and R. O. Gilbert. 2006 Defining postpartum uterine disease in cattle. Theriogenology 65:1516-1530

Shimazu, T., N. Tamura, and K. Shimazu. 2005. Aging of the autonomic nervous system. Nippon Rinsho 63:973-977.

Silvetti, M. S., F. Drago, and P. Ragonese. 2001. Heart rate variability in healthy children and adolescents is partially related to age and gender. Int. J. Cardiol. 81:169-174.

Sprecher, D. J., D. E. Hostetler, and J. B. Kaneene. 1997. A lameness scoring system that uses posture and gait to predict dairy cattle reproductive performance. Theriogenology 47:1179-1187.

Stubsjøen, S. M., A. S. Flø, R. O. Moe, A. M. Janczak, E. Skjerve, P. S. Valle, and A. J. Zanella. 2009. Exploring non-invasive methods to assess pain in sheep. Physiol. Behav. 98:640-648.

Terkelsen, A. J., H. Mølgaard, J. Hansen, O. K. Andersen, and T. S. Jensen. 2005. Acute pain increases heart rate: differential mechanisms during rest and mental stress. Auton. Neurosci. 121:101109.

Thong, T., K. Li, J. McNames, M. Aboy, and B. Goldstein. 2003. Accuracy of ultra-short heart rate variability measures. Pages 24242427 in Engineering in Medicine and Biology Society. Proceedings 
of the 25th Annual International Conference of the IEEE. Vol. 3. IEEE, New York, NY.

von Borell, E., J. Langbein, G. Després, S. Hansen, C. Leterrier, J. Marchant-Forde, R. Marchant-Forde, M. Minero, E. Mohr, A. Prunier, D. Valance, and I. Veissier. 2007. Heart rate variability as a measure of autonomic regulation of cardiac activity for assessing stress and welfare in farm animals - A review. Physiol. Behav. 92:293-316.

Walker, K. A., M. Horning, J. A. E. Mellish, and D. M. Weary. 2009. Behavioural responses of juvenile Steller sea lions to abdominal surgery: Developing an assessment of post-operative pain. Appl. Anim. Behav. Sci. 120:201-207.

Wesselmann, U., P. P. Czakanski, G. Affaitati, and M. A. Giamberardino. 1998. Uterine inflammation as a noxious visceral stimulus: Behavioral characterization in the rat. Neurosci. Lett. 246:73-76.

Wesselmann, U., and J. Lai. 1997. Mechanisms of referred visceral pain: Uterine inflammation in the adult virgin rat results in neurogenic plasma extravasation in the skin. Pain 73:309-317.
Wittrock, J. M., K. L. Proudfoot, D. M. Weary, and M. A. G. von Keyserlingk. 2011. Metritis affects milk production and cull rate of Holstein multiparous and primiparous dairy cows differently. J. Dairy Sci. 94:2408-2412.

Yamamoto, Y., R. L. Hughson, and J. C. Peterson. 1991. Autonomic control of heart rate during exercise studied by heart rate variability spectral analysis. J. Appl. Physiol. 71:1136-1142.

Yap, Y. G., A. J. Camm, G. Schmidt, and M. Malik. 2000. Heart rate turbulence is influenced by sympathovagal balance in patients after myocardial infarction-EMIAT substudy. Eur. J. Heart Fail. 2(S1):51.

Yukishita, T., K. Lee, S. Kim, Y. Yumoto, A. Kobayashi, T. Shirasawa, and H. Kobayashi. 2010. Age and sex-dependent alterations in heart rate variability: Profiling the characteristics of men and women in their 30s. J. Anti Aging Med. 7:94-99. 